\title{
PREVALENCE AND RISK FACTORS OF INTESTINAL HELMINTHIASIS AMONG THE CHILDREN OF BEGUN BARI SLUM, TEJGAON, DHAKA
}

\author{
Mandira Mukutmoni* and Hamida Khanum
}

Department of Zoology, University of Dhaka, Dhaka-1000, Bangladesh

\begin{abstract}
A cross sectional parasitological study was conducted among the underprivileged children of Begun Bari slum, Tejgaon, Dhaka during January 2015 to December 2016. Fecal samples were collected and then processed through formaldehyde-ether concentration technique. Prevalent helminths were Ascaris lumbricoides (27.68\%), Trichuris trichiura (21.57\%) and Taenia saginata (18.24\%). Male children were at high risk for helminth infection than females. The highest prevalence of A. lumbricoides (42.11\%) was observed among the children aged $10-12$ years and $T$. saginata (35.71\%) among $13-15$ years. The prevalence of A. lumbricoides (23\%) was the uppermost in the winter $(23 \%)$ and the lowest in the rainy season $(4.3 \%)$. Children of illiterate mothers $(91.89 \%)$, bare footers $(76.03 \%)$ and mud floor residents $(76.43 \%)$ were more prone to helminth infections $(\mathrm{p}<0.05)$
\end{abstract}

Key words: Helminth, formaldehyde-ether concentration, fecal, prevalence, risk factors

\section{INTRODUCTION}

Intestinal helminths are of great importance to the well-being of human (Savioli et al. 1992). World Health Organization (WHO) estimated that approximately 3.5 billion people are infected by intestinal parasites and about 450 million are ill as a result of these infections, the majority being children (WHO 2000). The common soil-transmitted helminths (Ascaris lumbricoides, hookworm and Trichuris trichiura) affect approximately 1.5 billion people, cause considerable morbidity and account for an estimated 5.2 million disability adjusted life years (DALYs) (Pullan et al. 2014). Hymenolepis nana, the dwarf tapeworm, is a common tapeworm in humans worldwide. H. nana infection occurs more frequently in warm climates and temperate zones such as Asia (Mirdha and Samantray 2002), Central and South America and Eastern Europe. Light $H$. nana infections are usually asymptomatic, whereas heavy infections with more than 2000 worms can induce a wide range of gastrointestinal symptoms and allergic responses (Marseglia et al. 2007). It is a zoonotic parasite and its principal definitive host are rodents which are very common in Bangladesh. The incidence of taeniasis is common in developing countries, including Bangladesh, where people have a culture of rearing domestic animals keeping them in close contact.

*Author for correspondence: <mukutmoni.zoo@du.ac.bd>.

(c) 2017 Zoological Society of Bangladesh DOI: http://dx.doi.org/10.3329/bjz.v45i2.35707 
The high prevalence of the parasites is usually correlated with poverty, poor environmental hygiene and deprived health services (Uddin and Khanum 2006). Children are more unprotected to helminth infections which are also linked with depressed growth and weakened intellectual functions (Khanum et al. 2010). Millions of children survive without adequate family care, guidance and protection, mostly in Asia, Africa and Latin America. For the establishment and welfare of society; children need to grow up in a sound and secure environment preserving their rights, privileges and facilities to live with proper health, moral and social comfort (UNICEF 2002).

Control of parasites utilizing the fecal-oral or skin route of transmission will depend on the knowledge of the aspects contributing to the spread of such infection. The aim of the present study was to observe the season, age and gender related pattern of helminth infections affecting underprivileged children. Its major motto was to observe the socioeconomic, hygienic conditions and to plan further research work to adopt suitable preventive measures.

\section{MATERIAL AND METHODS}

The present study was conducted among children aged 01-15 years of Begun Bari slum, Tejgaon, Dhaka. The period of study was from January, 2015 to December, 2016. One hundred and fifty nine fecal samples were tested in the Parasitology Laboratory, Department of Zoology, University of Dhaka. Stool samples were collected in screw capped, labeled plastic container, which were distributed to patients one day prior to the day of collection. Stool samples were subjected for complete examination - gross and direct microscopic examination (saline and iodine preparation) within 1 to 2 hours of collection. Samples were re-examined by applying formaldehyde-ether concentration method (Cheesbrough 1987). Structured questionnaire was followed to obtain data on literacy level of the mothers, types of toilets and houses, sanitation sense of the children. Data were analyzed using version 16 of SPSS. Associations between proportions were explored in $\chi^{2}$ tests. A $\mathrm{p}$ value $<0.05$ was considered indicative of a statistically significant.

\section{RESULTS AND DISCUSSION}

In the present study, Ascaris lumbricoides showed the maximum prevalence $(27.67 \%)$ comprising the highest prevalence $(16.98 \%)$ in male. T. saginata showed the second highest prevalence (18.24\%); peak (13.21\%) in male (Table 1). The result is supported by another work conducted in Bali, Indonesia which found significantly higher prevalence of $T$. saginata in males $(82.1 \%)$ than in females (17.9\%) (Wandra et al. 2006). T. trichiura (20.75\%) was also moderately 
prevalent; topmost (16.95\%) in male (Table 1). Similar result was found by Uddin and Khanum (2008) and Kumar et al. (2017).

Table 1. Prevalence of helminth parasites according to gender

\begin{tabular}{llccc}
\hline Parasites & Sex & $\begin{array}{c}\text { Total number } \\
\text { of samples }\end{array}$ & $\begin{array}{c}\text { Number of positive } \\
\text { samples }\end{array}$ & $\begin{array}{c}\text { Prevalence } \\
\text { (\%) }\end{array}$ \\
\hline A. lumbricoides & Male & 159 & 27 & 16.98 \\
& Female & & 17 & 10.69 \\
T. trichiura & Total & & 44 & 27.67 \\
& Male & 27 & 16.95 \\
Hookworm & Female & 6 & 3.77 \\
& Total & Male & 33 & 20.75 \\
& Female & 10 & 6.29 \\
H. diminuta & Total & Male & 1 & 0.63 \\
& Female & 11 & 6.92 \\
H. nana & Total & 6 & 3.77 \\
& Male & 4 & 2.52 \\
T. saginata & Female & 10 & 6.29 \\
& Total & 13 & 8.18 \\
& Male & 7 & 4.40 \\
& Female & 20 & 12.58 \\
& Total & 27 & 13.21 \\
& & 6 & 5.03 \\
& & 33 & 18.24 \\
\hline
\end{tabular}

In the present study, A. lumbricoides was the most prevalent $(42.11 \%)$ among the children aged 10-12 years old (Table 2). Dada-Adegbola et al. (2005) found $A$. lumbricoides as the most prevalent among all the children, with a prevalence of $81.6,63.3$ and $52.4 \%$ among the children aged $12-17,6-11$ and 0 - 5 years respectively. The uppermost prevalence of $A$. lumbricoides implies the high rate of egg production, suitable environment to keep those eggs alive, poor sanitation and ingesting raw vegetables or using contaminated hands. The second highest prevalence of A. lumbricoides (38.09\%) was observed among the children aged $4-6$ years old and the next was of $T$. trichiura (30.95\%) among the children aged 4 - 6 years old. The present result is agreed by another study conducted by Flores et al. (2001). H. nana was prevalent among the age group 13 - 15(21.43\%) and 10 - 12 (21.05\%); T. saginata (35.71\%) midst $13-15$ and hookworm (28.95\%) among 7 - 9 (Table 2) in the present study. Afia and Udoldang (2016) found 7 - 8 years aged children as the highest helminth prevalent (94.3\%) group.

In the present study, the prevalence of $A$. lumbricoides was the uppermost in the winter $(23 \%)$ and the lowest in the rainy season $(4.3 \%)$. Both $\mathrm{H}$. diminuta (12\%) and $H$. nana (10\%) was prevalent in summer. (Fig. 1). Kumar et al. (2014) 
found the highest prevalence of helminths in autumn $(80.5 \%)$ while it was the lowest in the months of spring (43.9\%).

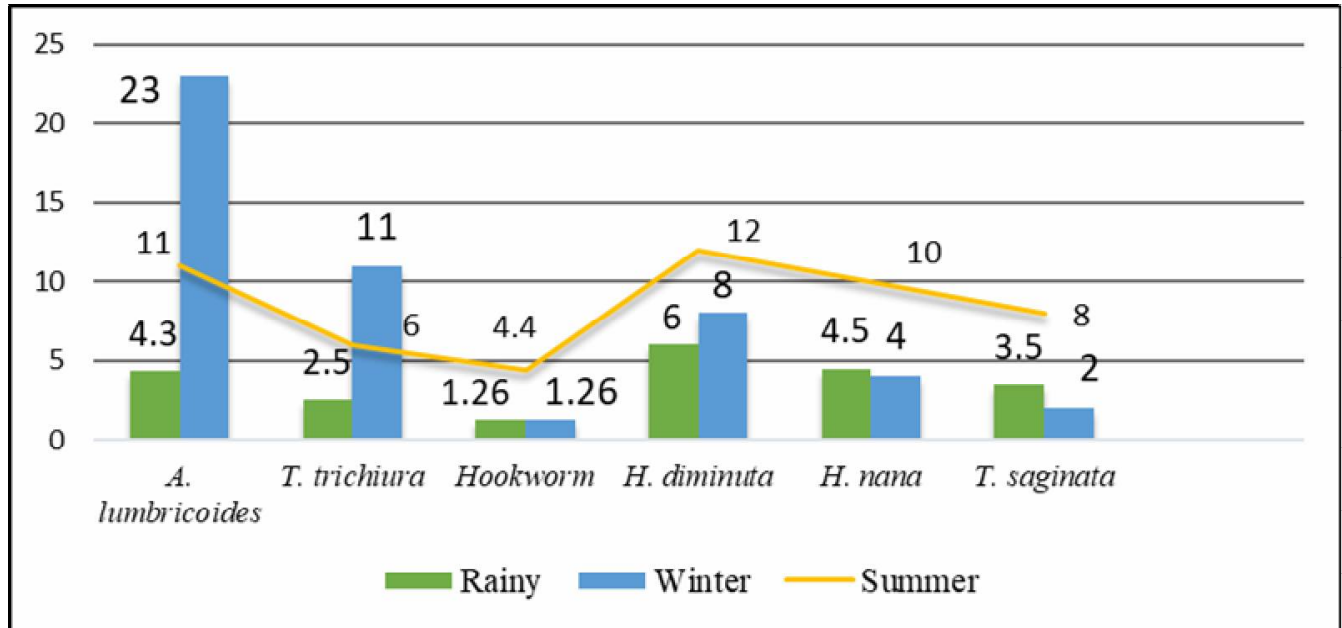

Fig. 1. Seasonal prevalence of helminths among children.

Table 2. Prevalence of parasites according to age groups

\begin{tabular}{|c|c|c|c|c|c|c|c|c|c|c|c|c|c|}
\hline \multirow{2}{*}{$\begin{array}{l}\text { Age } \\
\text { group }\end{array}$} & \multirow{2}{*}{$\begin{array}{l}\text { No. of } \\
\text { children }\end{array}$} & \multicolumn{2}{|c|}{$\begin{array}{c}\text { A. } \\
\text { lumbricoides }\end{array}$} & \multicolumn{2}{|c|}{$\begin{array}{c}T . \\
\text { trichiura } \\
\end{array}$} & \multicolumn{2}{|c|}{$\begin{array}{l}\text { Hook- } \\
\text { worm }\end{array}$} & \multicolumn{2}{|c|}{$\begin{array}{c}H . \\
\text { diminuta }\end{array}$} & \multicolumn{2}{|c|}{$\begin{array}{c}H . \\
\text { nana }\end{array}$} & \multicolumn{2}{|c|}{$\begin{array}{c}T . \\
\text { saginata }\end{array}$} \\
\hline & & $\mathrm{n}$ & $(\%)$ & $\mathrm{n}$ & (\%) & $\mathrm{n}$ & $(\%)$ & $\mathrm{n}$ & $(\%)$ & $\mathrm{n}$ & (\%) & $\mathrm{n}$ & (\%) \\
\hline $01-03$ & 32 & 10 & 31.25 & 4 & 12.50 & 0 & 0 & 2 & 6.25 & 0 & 0 & 4 & 12.50 \\
\hline $04-06$ & 42 & 16 & 38.09 & 13 & 30.95 & 0 & 0 & 0 & 0 & 6 & 14.28 & 7 & 16.67 \\
\hline $07-09$ & 38 & 5 & 13.16 & 8 & 21.05 & 11 & 28.95 & 4 & 10.53 & 4 & 10.53 & 2 & 5.26 \\
\hline $10-12$ & 19 & 8 & 42.11 & 4 & 21.05 & 0 & 0 & 2 & 10.53 & 4 & 21.05 & 6 & 31.58 \\
\hline $13-15$ & 28 & 5 & 17.86 & 4 & 14.28 & 0 & 0 & 2 & 7.14 & 6 & 21.43 & 10 & 35.71 \\
\hline
\end{tabular}

Urbanization is one of the major reasons behind the tendency of living in slums facing different hardships. Underprivileged living condition may increase the risk of contamination of intestinal helminths. In the present study, poor household sanitation was identified as a risk factor for intestinal helminthiasis $\left(\chi^{2}=63.32, p<0.05\right)$. Children of illiterate mothers (unable to read and write) were more prone to helminth infestation (91.89\%) (Table 3) which is supported by another study conducted among the Mexican children; revealed low maternal education level was highly associated with parasitic infection ( $\mathrm{p}<0.001)$ (Quihui et al. 2006). Kumar et al. (2017) found that children with low educational status were more likely to have intestinal parasites too. 
Mud floor was a contributing factor for helminth $(76.42 \%)$ infestation. Community toilet users were detected as more vulnerable to helminth infestation (73.13\%) (Table 3). Onyido et al. (2017) found that several predisposing factors to worm infection like the absence of toilet facilities at home and schools, inadequate drinking water sources and poor hygienic attitude of the children were significantly linked with intestinal worm infestation. Footwear was a vital factor for helminth infection $(\mathrm{p}<0.05)$ in the present study; having no footwear showed higher prevalence (76.03\%) than having foot ware (34.21\%). Non-hand wash user (80\%) and irregular nail trimmer $(90 \%)$ were also more prone to helminth infestation (Table 3). Long nail is a contributing factor for acquiring and ingesting egg of parasites more easily.

Table 3. Household and educational factors increasing risk of helminth infections

\begin{tabular}{lccc}
\hline Factors & $\begin{array}{c}\text { No. of samples } \\
\text { examined }\end{array}$ & $\begin{array}{c}\text { No. of } \\
\text { infected }\end{array}$ & $\begin{array}{c}\text { Prevalence } \\
\text { (\%) }\end{array}$ \\
\hline $\begin{array}{l}\text { Educational status of mothers } \\
\text { Illiterate }\end{array}$ & 74 & 68 & 91.89 \\
Primary education & 44 & 29 & 65.91 \\
Secondary and above & 41 & 8 & 19.51 \\
Type of house ${ }^{* *}$ & & & \\
Mud floor & 123 & 94 & 76.42 \\
Brick floor & 36 & 11 & 30.56 \\
Types of toilet $^{* *}$ & & & 73.13 \\
Community & 134 & 98 & 28 \\
Personal & 25 & 7 & 76.03 \\
Use of shoes & & & 34.21 \\
Bare footed & 121 & 92 & 62.09 \\
Wear shoes & 38 & 13 & 80 \\
Hand wash & & & \\
With soap & 124 & 77 & 36.23 \\
Without soap & 35 & 28 & 90 \\
Trimming nails & & & \\
Regularly & 70 & 24 & 81 \\
Irregularly & 89 & & \\
\hline
\end{tabular}

${ }^{* *} \mathrm{p}<0.05=$ Significant association with the factors.

Usually children who pick up and eat food from the ground, possess higher risk of helminth infection. Moreover, in the slum areas, meals remain unveiled and exposed to heavy wind, domestic animals containing parasite eggs. The findings are similar to another study conducted in Sri Lanka (Gunawardena et al. 2011). Similar results were obtained in study conducted among Turkish school children ( $\mathrm{p}<0.001$ ) (Ostan et al. 2007). From the present study, quite high occurrence of intestinal helminths among the underprivileged children was 
documented which raises question about literacy and everyday hygiene practices. Emphasis is needed on both medication and prevention. Treatment with anthelminthic drugs reduces the transmissibility of parasites by reducing worm load and shedding of eggs (WHO 2002); with a single dose of anthelminthics resulting in cure rates of $88 \%$ for $A$. lumbricoides and $78 \%$ for hookworm (Keiser et al. 2008).

Considering the findings, it can be concluded that intestinal helminth infections are important health problems among underprivileged children. Exposure to infection is influenced by climate, poverty, ignorance, lack of access to safety measures and personal hygiene. These infections affect the psychological and physical development of a child. Therefore, an extensive design is necessary to implement a proper control strategy to mitigate these infections.

\section{LITERATURE CITED}

AFIA, U. U. and UDOIDANG, I. N. 2016. Prevalence of helminthiasis among primary school pupils in Ibesikpo Asutan local government area, Akwa Ibom State Nigeria. IJSD. 6: 121-127.

CHEesbrough, M. 1987. Medical Laboratory Manual for Tropical Countries. Blackworth Co. Publishers. 570 p.

DADA-ADEGBOlA, H. O., OlUWATOBA, A. O. and FAlADE, C.O . 2005. Prevalence of multiple intestinal helminths among children of a rural community. Afr. J. Med. Med. Sci. 34(3): 263267. PMID: 16749359.

FLORES, A., ESTENBAN, J., ANGLES, R. and MAS-COMA, S. 2001. Soil transmitted helminth infection at very high altitude in Bolivia. Trans. R. Soc. Trop. Med. Hyg. 95: 272-277.

GUNAWARDENA, K., KUMARENDRAN, B., EBENEZER, R., GUNASINGHA, M. S., ARUNASALAM PATHMESWARAN, A. and DE SILVA, N. 2011. Soil transmitted helminth infestation among plantation sector schoolchildren in Sri Lanka: Prevalence after ten years of preventive chemotherapy. PLoS Negl. Trop. Dis. e1341. doi: 10.1371/journal.pntd.0001341.

KEISER, J. and UTZINGER, J. 2008. Efficacy of current drugs against soil-transmitted helminth infections: systematic review and meta-analysis. JAMA. 299: 1937-48.

KUMAR, S., SINGH, J. and KUMAR, A. 2017. Prevalence and correlation of soil transmitted helminth infection to the degree of anemia and nutritional status among pediatric patients of age group 614 years in Kishanganj, Bihar, India. Int. J. Contemp. Pediatr. 4(1): 223-231.

KUMAR, H., JAIN, K. and JAIN, R. 2014. A study of prevalence of intestinal worm infestation and efficacy of antihelminthic drugs. Med. J. Armed Forces India 70(2): 144-148. doi: 10.1016/ j.mjafi.2013.12.009

KHANUM, H., ISLAM, R. and PARVIN, S. 2010. Occurrence of egg and larvae of gastrointestinal nematodes in nails of street inhabitants in Dhaka city. J. Life Earth Sci. 5: 75-79.

MARSEGliA, G. L., MARSEGliA, A., LICARI, A., CASTEllaZZI, A. M. and CIPRANDI, G. 2007. Chronic urticaria caused by Hymenolepis nana in an adopted girl. Allergy 62: 821-822.

MIRDHA, B. R. and SAMANTRAY, J. C. 2002. Hymenolepis nana: a common cause of paediatric diarrhoea in urban slum dwellers in India. J. Trop. Pediatr. 48: 331-334. 
ONYIDO, A.E., ANUMBA, J.U., EZECHUKWU, G.C., UGHA, C., UMEANAETO, P.U. and IWUEZE, M.O. 2017. Intestinal helminth infections among primary school pupils in Ekwulumili Community, Nnewi South Local Government Area, Anambra State. Nigerian J. Parasitol. 38(2): 17-24.

OSTAN, I., KILIMCIOLU, A. A., GIRGINKARDELER, N., OZYURT, C. B., LIMONCU, M. E. and OK, U. Z. 2007. Health inequities: lower socio-economic conditions and higher incidences of intestinal parasites. BMC Public Health 7: 342-50.

PULLAN, R. L., SMITH, J. L., JASRASARIA, R. and BROOKER, S. J. 2014. Global numbers of infection and disease burden of soil transmitted helminth infections in 2010. Parasit. Vectors 2: 7-37.

QUiHUi, L., VAlENCIA, M. E., CROMPTON, D. W. T., PHILliPS, S., HAGAN, P. and MORALES, G. 2006. Role of the employment status and education of mothers in the prevalence of intestinal parasitic infections in Mexican rural school children. BMC Public Health 6: 225-32.

SAVIOLI, I., BUNDY, D. A. P. and TOMKINS, A. 1992. Intestinal parasitic infections: a solvable health problem. Trans. R. Soc. Trop. Med. Hyg. 86: 351-354.

UDDIN, M. H. and KHANUM, H. 2006. Hemoglobin level among adolescent girls and it's relation to intestinal parasites. Bangladesh J. Zool. 32(2): 183-188.

UDDIN, M. H. and KHANUM, H. 2008. Intestinal parasitic infestation and anaemic status among the adolescent boys in Bangladesh. Univ. J. Zool. Rajshahi Univ. 27: 63-65.

UNICEF (UNITED NATIONS CHILDREN'S FUND). 2002. Poverty and exclusion among urban children. UNICEF Report. Innocenti Digest Center, Italy, pp. 2-7. Retrieved from http://www.unicef-irc.org/publications/pdf/digest10e.pdf .

WANDRA, T., SUTISNA, P., DHARMAWAN, N. S., MARGONO, S. S., SUDEWI, R., SUROSO, T., CRAIG, P. S. and ITO, A. 2006. High prevalence of Taenia saginata taeniasis and status of Taenia solium cysticercosis in Bali, Indonesia, 2002-2004. Trans. R. Soc. Trop. Med. Hyg. 100(4): 346-53.

WHO (WORLD HEALTH ORGANIZATION). 2000. The World Health Report. conquering suffering enriching humanity. World Health Organization, Geneva. pp. 1-205.

WHO (WORLD HEALTH ORGANIZATION). 2002. The World Health Report. Reducing risk, promoting healthy life. World Health Organization, Geneva. pp. 7-247. 